\title{
环糊精衍生物在金属催化有机合成中的应用
}

\author{
沈海民纪红兵* \\ (中山大学化学与化学工程学院 广州 510275)
}

\begin{abstract}
摘要 综述了环糊精(包括 $\alpha$-环糊精, $\beta$-环糊精和 $\gamma$-环糊精)衍生物在金属催化有机合成中的应用, 主要包括其作为金属 离子配体、金属纳米粒子稳定剂和反相相转移催化剂在氧化、水解、还原、偶联等金属催化反应中的应用. 其中环糊 精衍生物作为金属离子配体应用最广，由于环糊精部分与底物形成包结络合物，拉近了底物和具有催化活性的金属离 子的距离, 并固定了底物的反应部位, 往往可以显著提高催化反应的反应速率, 增强反应的区域选择性和对映选择性. 关键词 环糊精衍生物; 金属催化; 有机合成
\end{abstract}

\section{Application of Cyclodextrin Derivatives in Metal-Catalyzed Organic Synthesis}

\author{
Shen, Haimin Ji, Hongbing* \\ (School of Chemistry and Chemical Engineering, Sun Yat-sen University, Guangzhou 510275)
}

\begin{abstract}
The application of cyclodextrin ( $\alpha$-cyclodextrin, $\beta$-cyclodextrin and $\gamma$-cyclodextrin) derivatives in metal-catalyzed organic synthesis has been reviewed, especially as ligands of metal ion, stabilizers of metal nanoparticles and inverse phase transfer catalysts in oxidation, hydrolysis, reduction, coupling reactions and so on. The cyclodextrin derivatives employed as ligands of metal ion are used most widely in which the formation of inclusion complexes between the cyclodextrin unit and substrate narrows the distance between the substrate and the metal ion, and fixes the reaction site of the substrate. Thus, the reaction rate can be increased obviously, and the regioselectivity and enantioselectivity can be enhanced remarkably.

Keywords cyclodextrin derivatives; metal-catalysis; organic synthesis
\end{abstract}

环糊精(cyclodextrin，简称 $\mathrm{CD}$ )主要包括 $\alpha$-环糊精、 $\beta$-环糊精和 $\gamma$-环糊精, 是一类由 $D-(+)$-吡喃葡萄糖单元 通过 $\alpha-1,4$-糖苷键连接而成, 呈截顶圆锥状的环状低聚 糖, 其中 $\beta$-环糊精价廉易得, 应用最广. 在其结构特征 上，组成环糊精的 $D-(+)$-吡喃葡萄糖单元的着基位于 截顶圆锥的两个边缘, C-3 和 C-5 上的 $\mathrm{H}$ 原子位于截顶 圆锥的内部空腔. 因此, 环糊精 “外壁亲水” 而 “内腔 疏水” ${ }^{[1]}$, 在水中能够像酶一样为疏水底物提供一个疏 水环境, 广泛应用于氧化、还原、水解、加成等各种有 机反应 ${ }^{[2]}$. 但是在环糊精分子中只有羟基一种官能团, 并且这些羟基易形成分子内氢键, 使环糊精分子结构具 有很强的刚性, 在与具有各种形状和官能团的客体分子 相互作用时, 环糊精的结构很难发生相应的拓扑变化. 同时, 环糊精在大多数有机溶剂中溶解性不好, 仅溶于
水和少数强极性有机溶剂, 这就使其在有机溶剂中的应 用受到很大限制 ${ }^{[3]}$. 为了改变环糊精的物理和化学性质, 拓展其应用范围, 可以选择性的对环糊精的羟基进行化 学修饰, 将羟基转化成目标官能团. 尽管对环糊精众多 羟基进行选择性的修饰是件极具挑战性的工作，但是在 广大有机合成工作者不解的努力下，目前已有大量环糊 精衍生物被成功合成出来 ${ }^{[3 \sim 5]}$.

环糊精衍生物的大量出现为环糊精用于催化有机 合成提供了更大的选择空间. 环糊精衍生物不仅可以作 为人工酶 ${ }^{[6 \sim 9]}$ 、超分子光学手性源 ${ }^{[9,10]}$ 和微通道反应 器 ${ }^{[9,11]}$ 直接用于有机合成反应，还可以用于金属催化有 机合成反应. 目前, 环糊精衍生物在金属催化有机合成 反应中的应用主要有以下 3 种: (1)作为金属离子配体, 与具有催化活性的金属离子形成络合物作为人工金属

\footnotetext{
*E-mail: jihb@mail.sysu.edu.cn; Tel.: 020-84113658, Fax: 020-84113654.

Received October 24, 2011; revised December 5, 2011; published online January 6, 2012.

Project supported by the National Natural Science Foundation of China (Nos. 21176268, 21036009), the Higher-Level Talent Project for Guangdong Provincial Universities and the Fundamental Research Funds for the Central Universities.

国家自然科学基金(Nos. 21176268, 21036009)和 2010 年广东省高等学校高层次人才、中央高校基本科研业务费专项资金资助项目.
} 
酶催化有机合成反应，在这里金属离子是催化活性中 心, 环糊精部分起底物包结作用, 将底物固定在金属离 子附近 ${ }^{[12 ~ 14] ;}$ (2)作为具有催化活性的金属纳米粒子稳 定剂, 增加金属纳米粒子的水溶性和稳定性, 催化有机 合成反应，同时环糊精部分还具有一定的底物选择和输 送功能 ${ }^{[15 ~ 17]}$; (3)作为反相相转移催化剂, 用于水溶性贵 金属离子催化水相一有机相两相反应, 将水不溶性底物 转移到两相界面区域，与水相中的贵金属催化剂接触反 应 $^{[15,17 ~ 19]}$. 本综述结合本课题组已进行的研究 ${ }^{[20 ~ 24]}$, 详 细介绍了环糊精衍生物在金属催化有机合成反应中的 应用。

\section{1 金属离子配体}

环糊精衍生物, 基本是 $\beta$-环糊精衍生物与金属离子 形成络合物作为超分子催化剂, 催化有机合成反应, 其 催化活性中心为金属离子, $\beta$-环糊精衍生物作为金属离 子的配体, 并具有底物包结作用. $\beta$-环糊精部分对底物 的包结作用拉近了底物与催化活性中心的距离, 使底物 和催化活性中心处于较佳的空间几何位置, 增强了该超 分子催化剂的催化活性和对映选择性. 该类超分子催化 剂往往可以明显提高反应速率和反应的对映选择性, 具 有一定的仿生酶催化效果, 目前主要应用于催化氧化、 水解和还原反应. 早在 1998 年, Breslow 等 ${ }^{[2]}$ 就对 $\beta$-环 糊精衍生物作为金属离子配体, 形成超分子仿生催化剂 仿生催化有机合成反应进行了详细的综述, 本综述在其 基础上, 总结了近年来该领域新的研究进展, 比较系统 的对 $\beta$-环糊精衍生物作为金属离子配体进行了介绍, 同 时也对 $\beta$-环糊精衍生物作为金属纳米粒子稳定剂和反 相相转移催化剂进行了全面综述.

\section{1 氧化反应}

$\beta$-环糊精衍生物作为金属离子配体, 与金属离子形 成络合物催化氧化反应, 主要包括烯烃的催化氧化、类 固醇化合物的催化羟基化和硫醚的不对称催化氧化反 应，与金属卟啉的结合使 $\beta$-环糊精衍生物的金属络合物 具有更高的仿生催化效果, 高选择性的对底物的特定部 位进行催化氧化.

\subsection{1 烯烃}

Breslow 等 ${ }^{[25]}$ 以 $\beta$-环糊精衍生物 1 和 2 作为金属离 子 $\mathrm{Mn}(\mathrm{III})$ 的配体, 形成金属离子络合物, 作为催化剂催 化环氧化二苯乙烯衍生物(Eq. 1), 由于 $\beta$-环糊精部分对 底物的包结作用, 使底物的反应基团固定在催化活性中 心附近, 高效的实现了烯烃的环氧化反应. 而当 $\beta$-环糊 精衍生物 3 作为金属离子 $\mathrm{Mn}(\mathrm{III})$ 的配体时, 催化活性较 差, 主要是由于底物与 $\mathbf{3}$ 形成包结络合物的空间几何位 置不利于底物反应基团与催化活性中心接触.

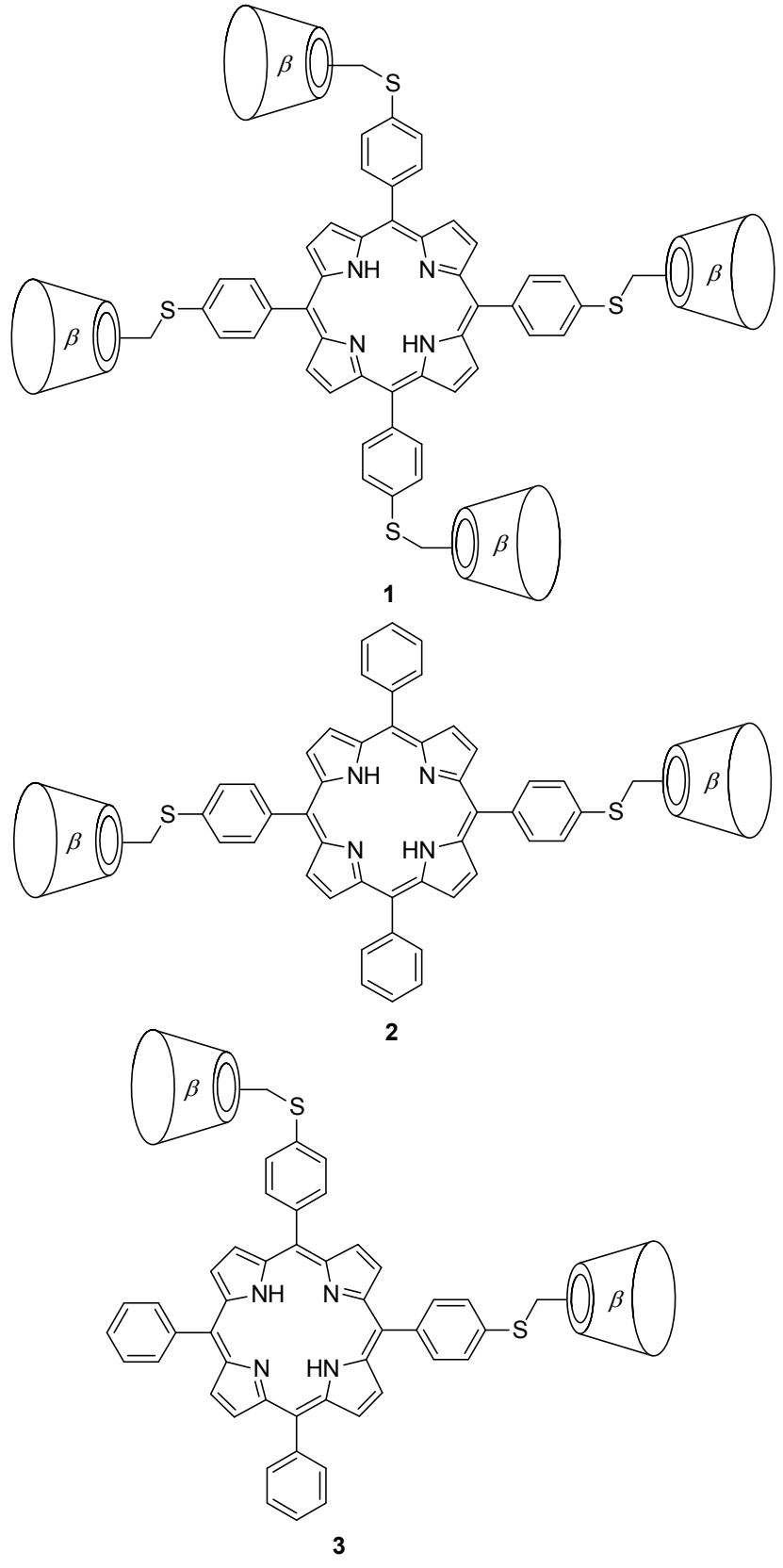

Karakhanov 等 ${ }^{[26]}$ 以具有 $\mathrm{CN}$ 的 $\beta$-环糊精衍生物 4 和 5 作为金属离子 $\mathrm{Pd}^{2+}$ 的配体, 形成金属离子络合物, 催化水不溶性烯烃水相一有机相两相 Wacker 氧化反应. $\beta$-环糊精衍生物 4 和 $\mathbf{5}$ 不仅作为金属离子配体，还具有 相转移的作用, 与水不溶性底物形成包结物, 拉近了底 物与金属离子的距离, 促进反应进行. 其中 4 作为 $\mathrm{Pd}^{2+}$ 的配体时，催化效果最佳，以 1-辛烯为底物, 2-辛酮的收 率和选择性均在 $90 \%$ 以上.

另外, French 等 ${ }^{[27,28]}$ 以 $\beta$-环糊精衍生物 6 为金属钉 离子的配体, 形成金属络合物，作为 $\beta, \beta$-胡萝卜素氧化 酶模型催化氧化裂解 $\beta, \beta$-胡萝卜素生成瑞叮醛(Eq. 2 ). 由于底物 $\beta, \beta$-胡萝卜素与 $\beta$-环糊精部分形成包结络合 


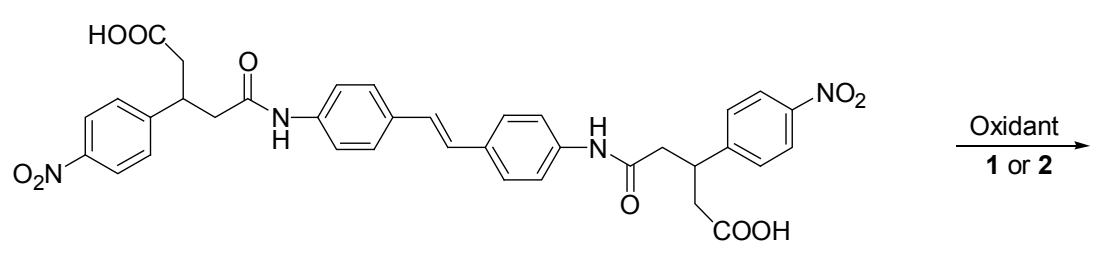<smiles>O=C(O)CC(CC(=O)Nc1ccc(C2OC2c2ccc(NC(=O)CC(CC(=O)O)c3ccc([N+](=O)[O-])cc3)cc2)cc1)c1ccc([N+](=O)[O-])cc1</smiles>
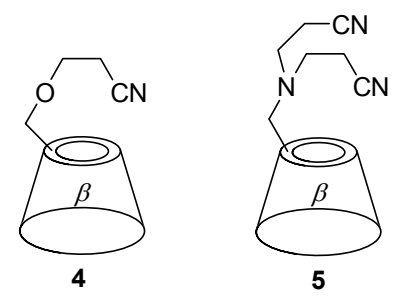

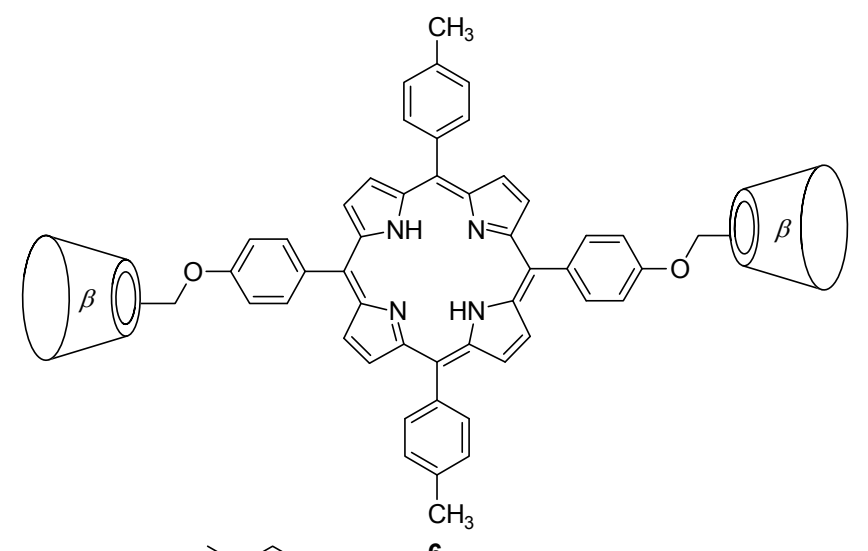<smiles>CC(C)=C/C=C(C)/C=C(C)/C=C/C=C(C)/C=C/C=C(C)/C=C/C1=C(C)CCCC1(C)C</smiles>

物, 将 $\beta, \beta$-胡萝卜素 $\mathrm{C}-15=\mathrm{C}-15^{\prime}$ 固定在金属钓离子附 近, 使氧化裂解反应高选择性的发生在 $\mathrm{C}-15=\mathrm{C}-15^{\prime}$ 处, 生成产物瑞叮醛. 当底物中一个环已烯环被苯环替代 时, 增加了底物与 $\beta$-环糊精部分的疏水相互作用, 催化 裂解反应只发生在 $\beta, \beta$-胡萝卜素 C- $15=\mathrm{C}-15$ '处.

\subsection{2 类固醇化合物}

$\beta$-环糊精衍生物作为金属离子配体催化类固醇化 合物氧化羟基化反应, 主要是作为人工合成的细胞色素 P-450 酶模型, 将 $\beta$-环糊精与 $\mathrm{Mn}(\mathrm{III})$ 卟啉结合起来, 高 选择性的实现了类固醇化合物的氧化着基化反应. Breslow 等 ${ }^{[29-33]}$ 分别以 $\beta$-环糊精衍生物 1, 7 10 等为金 属离子 $\mathrm{Mn}(\mathrm{III})$ 的配体, 作为细胞色素 P-450 酶模型催化 类固醇化合物氧化羟基化反应(Scheme 1). 首先通过酯 化反应将两个 $p$-叔丁基苯基连接到类固醇化合物上, 增 强类固醇化合物与 $\beta$-环糊精部分的包结性能, 两个磺酸 基有利于提高底物的水溶性, 高选择性的实现了在类固 醇化合物 C-9 位置的氧化羟基化, 然后通过水解可得到
C-9 位置选择性羟基化的类固醇化合物. $\beta$-环糊精部分 对底物的包结作用, 使底物的 C-9 位置固定在催化活性 中心 $\mathrm{Mn}(\mathrm{III})$ 附近, 是该仿生催化体系具有高选择性的 关键. 并且该超分子催化剂均具有较好的转化频率.

\subsection{3 硫醚}

硫醚到亚砜的不对称氧化一直是有机合成方法学 研究的热点, 水相不对称氧化硫醚生成亚砜更受到人们 的关注. Bonchio 等 ${ }^{[34]}$ 以 $\beta$-环糊精衍生物 11 14 为金属 离子 $\mathrm{Mo}(\mathrm{VI})$ 的配体, 形成金属络合物催化水相 $\mathrm{H}_{2} \mathrm{O}_{2}$ 不 对称氧化苯甲硫醚生成亚砜, 产物 $e e$ 在 $50 \%$ 左右, 并且 修饰基团在 C-6 位置时催化效果最佳. Skuraba 等 ${ }^{[35]}$ 以具 有 $o$-苯二酚和 $m$-苯二酚修饰基团的环糊精衍生物 15 和 16 为金属离子 $\mathrm{Mo}(\mathrm{V})$ 和 $\mathrm{Cu}(\mathrm{II})$ 的配体, 形成金属离子络 合物, 催化水相 $\mathrm{H}_{2} \mathrm{O}_{2}$ 不对称氧化芳基硫醚, 不仅提高了 反应速率, 还提高了反应的对映选择性. 产物 $e e$ 值最高 达到 $58 \%$. 

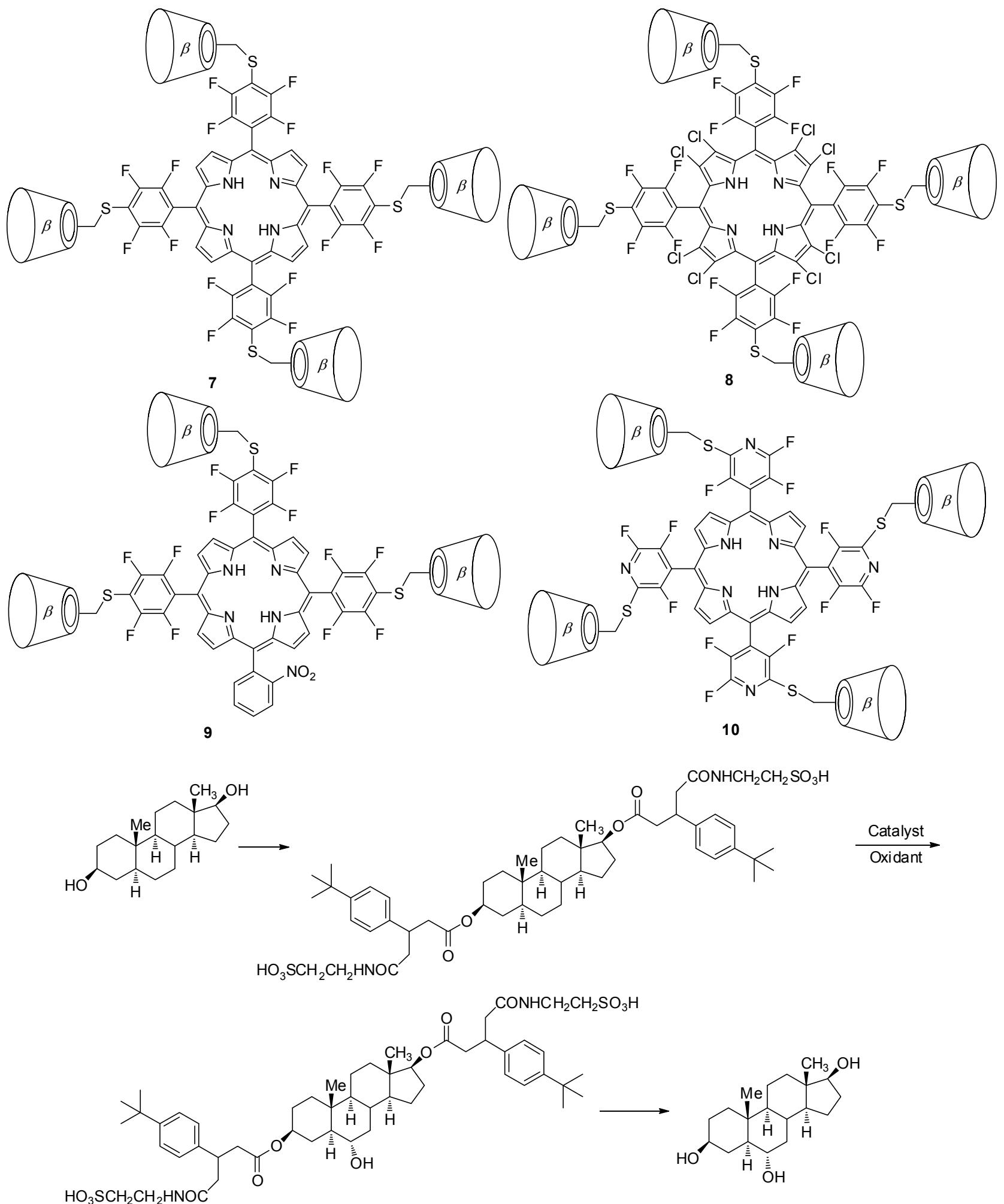

Scheme 1

另外，除了以上列举的催化氧化烯烃、类固醇化合 物和硫醚以外, Bonchio 等 ${ }^{\left[{ }^{[3]}\right.}$ 以甲基化 $\beta$-环糊精和 5,10, 15,20-四(4-磺酸基苯基)卟啉(17)形成 $2: 1$ 络合物, 作为 光氧化催化剂, 催化氧化生物小分子甲基氨酸甲酯和尿 嘧啶等, 并且对水中苯酚的氧化降解也具有较好的催化
活性. Kano 等 ${ }^{[37]}$ 报道了 $\beta$-环糊精二聚体 18 和 $5,10,15,20$ 四(4-磺酸基苯基)卟啉(17)形成 $1: 1$ 包结络合物作为 $\mathrm{Fe}(\mathrm{II})$ 的配体，形成金属离子络合物，该络合物在水溶 液中表现出很强的结合氧的能力, 与氧形成的加合物的 半衰期 $t_{1 / 2}$ 达 $30.1 \mathrm{~h}$. 但该超分子催化剂不稳定，易发生 

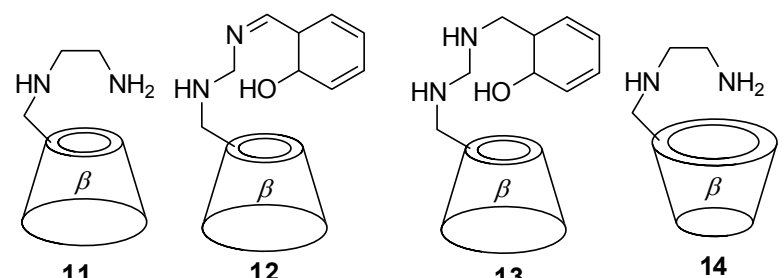

13

14
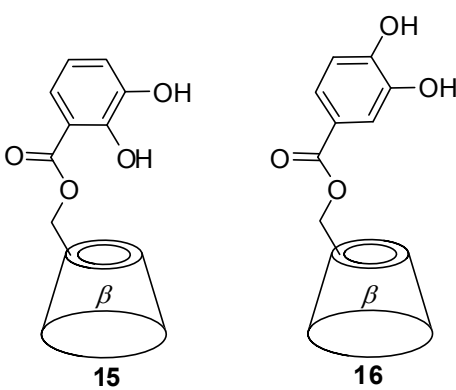

自氧化, 可通过对其进行修饰改性, 将其转化为有效的 超分子氧化催化剂.

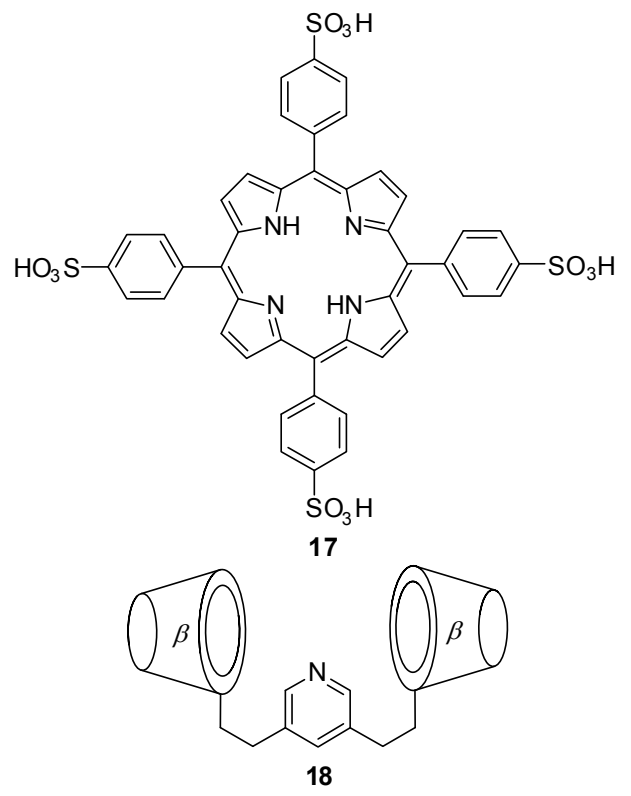

\section{2 水解反应}

$\beta$-环糊精衍生物作为金属离子配体，与金属离子形 成络合物催化水解反应, 往往具有极高的催化活性. 环 糊精衍生物中有的含有一个 $\beta$-环糊精部分, 有的含有两 个 $\beta$-环糊精部分, 甚至三个环糊精部分. 但其起催化作 用的催化活性中心为金属离子, 环糊精部分作为水解底 物或催化剂的包结部位对水解底物和催化剂进行空间 位置上的固定, 拉近底物和催化活性中心的距离, 促进 反应进行.

Dong 等 ${ }^{[38]}$ 以 $\beta$-环糊精衍生物 19 为金属 $\mathrm{Zn}^{2+}$ 的配 体, 形成金属离子络合物, 催化水解环状 4-叔丁基邻苯 二酚磷酸酯(Eq. 3). 研究结果显示, 当两个修饰基团处 于 $\beta$-环糊精相邻的两个吡喃葡萄糖环时, 催化活性最
高, 催化水解速率是 $\beta$-环糊精和金属 $\mathrm{Zn}^{2+}$ 组合作为催化 剂的 937 倍. 在该超分子催化剂中, $\mathrm{Zn}^{2+}$ 为酸催化中心, 咪唑基团为碱催化中心，二者协同作用催化反应进行. $\mathrm{Kim}$ 等 ${ }^{[39]}$ 以 $\beta$-环糊精衍生物 $\mathbf{2 0} \sim \mathbf{2 2}$ 为配体，与金属离 子 $\mathrm{Zn}^{2+}$ 形成金属离子络合物作为金属蛋白酶模型，催 化水解 $p$-硝基苯基乙酸酯, 将反应速率提高了近 300 倍. Barr 等 ${ }^{[40]}$ 以 $\beta$-环糊精衍生物 11 和 23 作为配体，与金属 离子 $\mathrm{Cu}^{2+}$ 形成络合物催化水解磷酸三酯(如 Eq. 4 所示), 显著提高了水解速率. 以磷酸(4-叔丁基-2-硝基苯基、二 甲基)酯为底物, 11 和 23 分别将水解速率提高了 95000 倍和 70000 倍, 并具有一定的底物选择性. $\mathrm{Li}$ 等 ${ }^{\left[{ }^{[1]}\right.}$ 以超 分子催化剂 25 作为水解酶催化水解 4,4'二硝基苯基碳 酸酯, 将水解反应速率提高了 4670 倍. 在该催化体系 中, 与 $\mathrm{Cu}^{2+}$ 络合的 $\mathrm{OH}$ 亲核进攻碳酸酯的羰基碳原子, 胍对形成的四面体中间态具有稳定作用，促进催化反应 进行.<smiles>NCCN(CCN)CCC1C2CC3CC(C2)CC1C3</smiles><smiles></smiles>

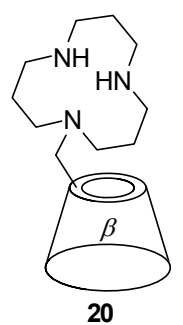

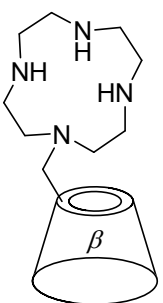

21

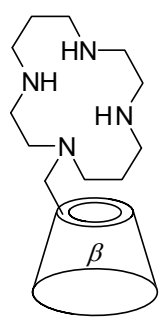

22

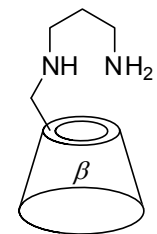

23

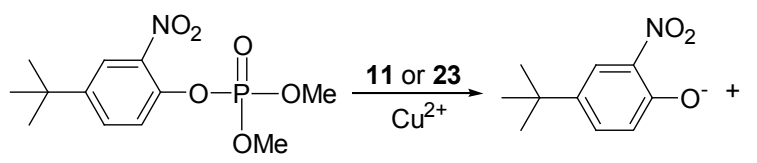

24<smiles>COP(=O)([O-])O[Na]</smiles>

另外, Breslow 等 ${ }^{[42 \sim 44]}$ 先后报道了 $\beta$-环糊精二聚体 26, 与金属离子 $\mathrm{Zn}^{2+}, \mathrm{Cu}^{2+}$ 和 $\mathrm{La}^{3+}$ 形成络合物催化水解 $p$-硝基苯基酯. $\beta$-环糊精二聚体通过对底物的包结对底 


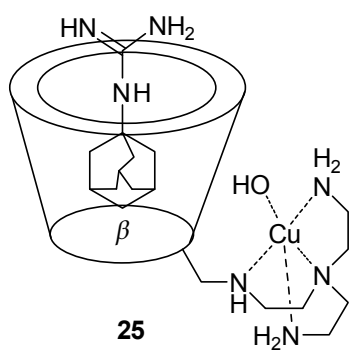

物产生一定的拉伸作用, 使酯键能够很好的接近具有催 化活性的金属离子，显著提高了水解速率，可将酯的水 解速率提高 $10^{4} \sim 10^{5}$ 倍. Jeon 等 ${ }^{\left[{ }^{[45}\right.}$ 以 $\beta$-环糊精二聚体 27 和 28 及其与金属离子 $\mathrm{Cu}^{2+}$ 形成的络合物为催化剂, 催 化水解 $p$-硝基苯基乙酸酯和 $p$-硝基苯基(金刚烷基甲酸) 酯. 对于 $p$-硝基苯基乙酸酯, $\beta$-环糊精二聚体 27 和 28 与 它们与金属离子 $\mathrm{Cu}^{2+}$ 形成的络合物具有相同的催化活

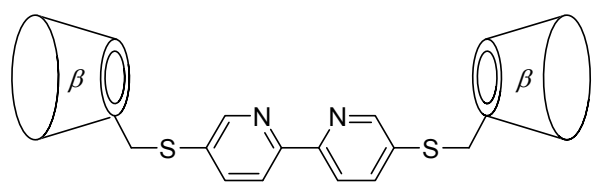

26

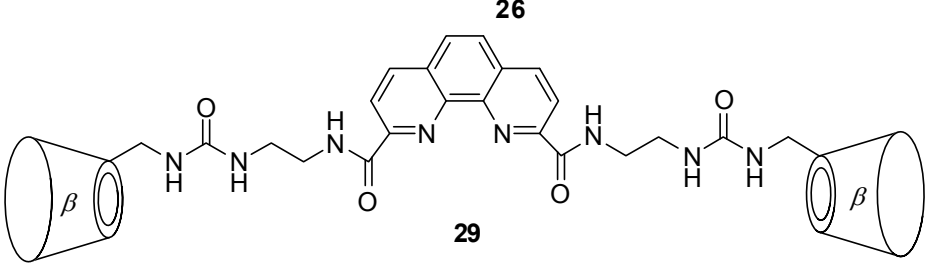

性，而当底物为 $p$-硝基苯基(金刚烷基甲酸)酯时，27 与 $\mathrm{Cu}^{2+}$ 形成的络合物具有最优的催化活性, 28 与 $\mathrm{Cu}^{2+}$ 形成 的络合物催化活性较差. Sallas 等 ${ }^{[46]}$ 以 $\beta$-环糊精二聚体 29 为金属离子 $\mathrm{Cu}^{2+}$ 的配体，形成金属离子络合物，催化 水解双 ( $p$-硝基苯基) 磷酸酯, 将水解速率提高了 $8 \times 10^{6}$ 倍. $\mathrm{Yan}$ 等 ${ }^{[47]}$ 以 $\beta$-环糊精二聚体 $\mathbf{3 0} \sim \mathbf{3 2}$ 为金属离子 $\mathrm{Cu}^{2+}$ 的配体, 形成金属离子络合物, 催化水解活性较差 的酯，也取得了很好的催化效果. 随后，Luo 等 ${ }^{[48]}$ 报道 了 $\beta$-环糊精二聚体 33 和 34 与 $\mathrm{Cu}^{2+}$ 形成金属离子络合 物催化水解 $p$-硝基苯基脂肪酸酯, Zhou 等 ${ }^{\left[{ }^{[4} \sim 51\right]}$ 报道了 $\beta$-环糊精二聚体 35 与 $\mathrm{Zn}^{2+}$ 形成的金属离子络合物及 $\beta$ 环糊精二聚体 36 和 37 与金属 $\mathrm{Zn}^{2+}$ 络合物 38 形成的新 的包结络合物催化水解 $p$-硝基苯基酯, Tang 等 ${ }^{[52,53]}$ 报道 了 $\beta$-环糊精二聚体 39 与 $\mathrm{Zn}^{2+}$ 和 $\mathrm{Cu}^{2+}$ 形成的金属离子络 合物催化水解 $p$-硝基苯基酯，均取得了很好的催化效

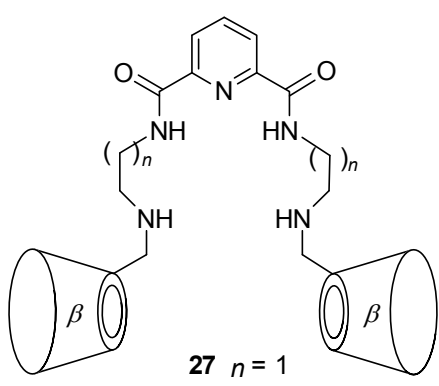

$28 n=2$

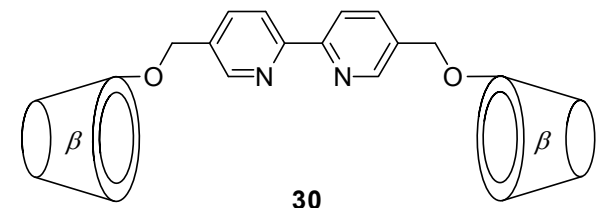

30

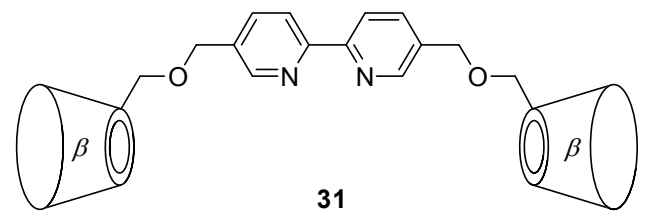

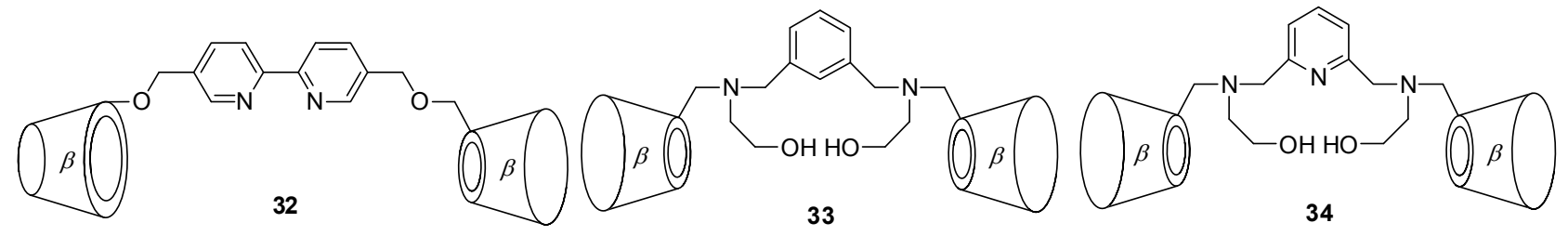

33

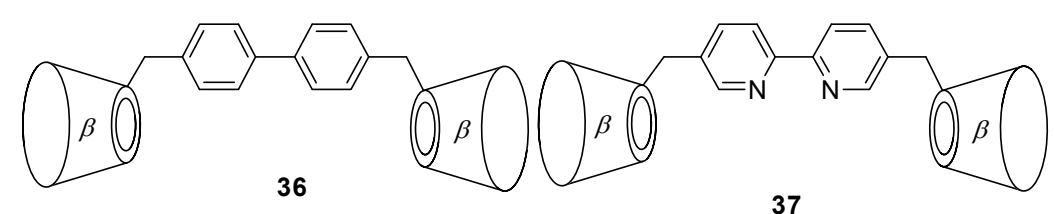

35<smiles>O=C(CNCc1cccc(CNCCC2C3C=CC4C(CC3)C42)n1)C1CC2CCC1C2</smiles>

39 
果. Zhou 等 ${ }^{[54]}$ 近年来对 $\beta$-环糊精二聚体与 $\mathrm{Zn}^{2+}$ 和 $\mathrm{Cu}^{2+}$ 形成金属离子络合物催化水解 $p$-硝基苯基酯和磷酸酯 进行了系统的研究, 显著提高了水解反应的速率, 取得 了很好的催化效果, 不断有新的研究成果报道出来. $\beta$ 环糊精空腔对水解底物的包结作用, 使水解底物固定在 具有催化活性的金属离子附近, 使水解反应顺利进行, 所用的金属离子目前报道的基本为 $\mathrm{Cu}^{2+}$ 和 $\mathrm{Zn}^{2+}$.

除了 $\beta$-环糊精二聚体外, Nakajima 等 ${ }^{[55]}$ 还报道了环 糊精三聚体 40 与 $N$-(4-咪唑基乙基)-4-叔丁基苯甲酰胺 形成包结络合物催化水解 $p$-硝基苯基酯. 其中两个 $\alpha$-环 糊精部分作为底物包结部位, $\beta$-环糊精部分包结催化剂 $N$-(4-咪唑基乙基)-4-叔丁基苯甲酰胺, 该超分子催化体 系表现出很强的底物选择性, 对 $p$-硝基苯基乙酸酯基本 没有催化活性, 而对包结性能更好的 $p$-硝基苯基(2-苯 甲酰氨基)乙酸酯具有很强的催化活性.

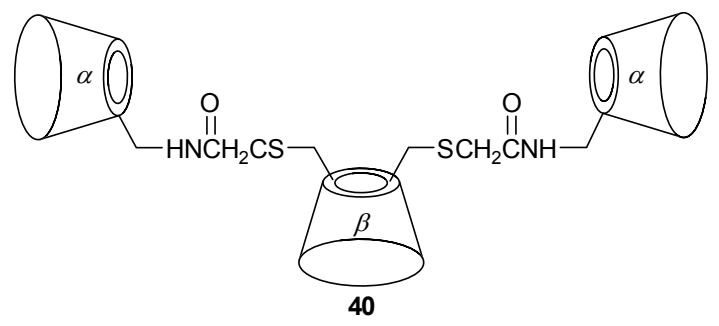

\section{3 还原反应}

$\beta$-环糊精衍生物作为金属离子配体, 与金属离子形 成金属离子络合物，催化有机还原反应，相关的文献报 道与催化氧化和水解反应相比较少. Reetz 等 ${ }^{\left[{ }^{[6]}\right.}$ 以有机 膦修饰的 $\beta$-环糊精衍生物 $\mathbf{4 1 \sim 4 3}$ 为配体, 与金属铑形 成络合物, 催化烯烃氢化和氢甲酰化反应. $\beta$-环糊精部 分对底物的包结和具有催化活性的金属铑协同作用, 使 该超分子催化剂具有很好的底物选择性和区域选择性. 在烯烃氢化反应中, 有利于结构中具有芳环的烯烃的氢 化还原, 在烯烃氢甲酰化反应中, 有利于生成端位醛. Wong 等 ${ }^{[57]}$ 以 $\beta$-环糊精衍生物 $6^{\mathrm{A}}, 6^{\mathrm{B}}$-双 (二苯基膦)- $6^{\mathrm{A}}, 6^{\mathrm{B}}$ 二脱氧一全甲基- $\beta$-环糊精(44)为配体，与 $\left[\mathrm{Rh}(\mathrm{COD})_{2}\right] \mathrm{BF}_{4}$ 形成金属络合物, 催化烯烃氢化还原反应. 以 $\alpha$-乙酰氨 基肉桂酸、 $\alpha$-乙酰氨基丙烯酸、衣康酸等为底物, 该超 分子催化剂在室温, $101 \mathrm{kPa}$ 下可将它们几乎定量转化, 产物 $e e$ 最高达到 $92 \%$.

Schlatter 等 ${ }^{[58,59]}$ 先后以 $\beta$-环糊精衍生物 $\mathbf{4 5} \sim \mathbf{4 8}$ 作为 金属钓离子的配体, 形成金属离子络合物, 催化氢化芳 香酮和脂肪酩(Eq. 5). $\beta$-环糊精部分与氢化底物形成包 结络合物, 将底物固定在具有催化活性的金属离子附 近, 不仅增加了底物的水溶性, 提高了反应速率, 也取 得了很好的对映选择性, 无论是芳香酮还是脂肪酤, 还 原产物醇的 $e e$ 最高均可达到 $90 \%$ 以上. 该催化剂

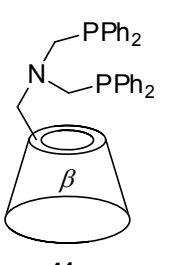

41

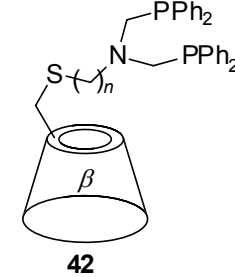

$n=2,3,4$

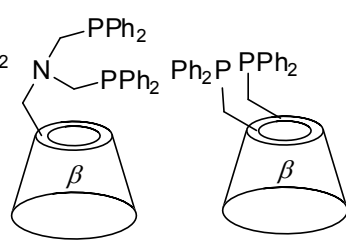

43
44

避免了反应底物结构中具有芳环结构才有利于反应进 行的局限, 通用性好.

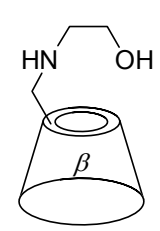

45

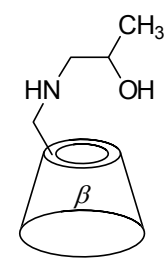

46

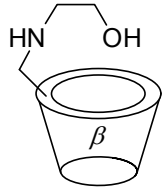

47

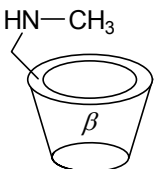

48

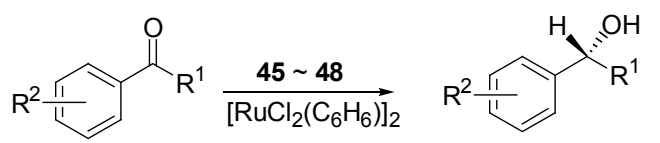

除了氧化、水解和还原反应, Yuan 等 ${ }^{[00,61]}$ 报道了 $\beta$ 环糊精二聚体与 $\mathrm{Ce}^{4+}$ 形成的金属离子络合物 49 催化鲁 米诺化学发光反应. 与催化剂不存在时基本不发光相 比, 49 的加入显著增强了鲁米诺的发光效率, $\beta$-环糊精 空腔对底物的包结作用, 拉近了鲁米诺与 $\mathrm{Ce}^{4+}$ 离子的 距离, 使二者处在较佳的催化位置, 提高了催化效率. Suresh 等 ${ }^{[62]}$ 报道了全(6-氨基-6-脱氧)- $\beta$-环糊精(50)作为 $\mathrm{Cu}^{+}$的配体，同时作为反应底物的超分子主体，催化咪 唑 $N$-芳基化反应(Eq. 6), 取得了很好的反应效果. 但是 $\beta$-环糊精衍生物作为金属离子的配体, 形成金属离子络 合物催化有机反应还基本局限在催化氧化和水解反应, 其它反应应用较少，所以开发 $\beta$-环糊精衍生物与金属离 子形成的络合物催化其它有机反应成为人们研究的热 点. $\beta$-环糊精衍生物作为金属离子配体，催化水相不对 称氢化还原反应，具有一定的研究价值.
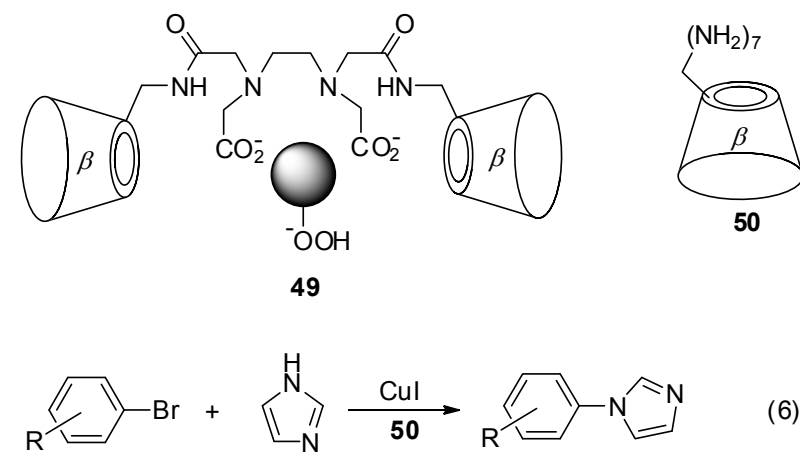


\section{2 金属纳米粒子稳定剂}

环糊精衍生物修饰贵金属及其氧化物纳米粒子，不 仅防止了金属纳米粒子在水相中的团聚，增加金属纳米 粒子的水溶性，提高金属纳米粒子在反应体系中的分 散, 并且环糊精部分还可以与反应底物形成包结络合 物, 将底物转移到金属离子表面, 有利于催化反应进行. 目前, 环糊精衍生物修饰贵金属及其氧化物纳米粒子作 为超分子催化剂主要应用在催化还原、偶联、氧化等反 应.

\section{1 还原反应}

Alvarez 等 ${ }^{[63]}$ 以全(6-颈基-6-脱氧)- $\beta$-环糊精(51)修 饰贵金属 $\mathrm{Pt}$ 和 $\mathrm{Pd}$ 纳米粒子, 并将该水溶性纳米粒子用 于催化氢化烯丙胺(如 Eq. 7 所示). 室温, $101 \mathrm{kPa} \mathrm{H}_{2}$ 下 底物转化率达到 $95 \%$ ～100\%, 并且该催化剂反应结束 后可以很容易的回收重复利用. Liu 等 ${ }^{[64]}$ 也以全(6-颈 基-6-脱氧)- $\beta$-环糊精(51)修饰的贵金属 $\mathrm{Pd}$ 纳米粒子催化 氢化烯烃(如 Eq. 8 所示), 提高了 $\mathrm{Pd}$ 纳米粒子的水溶性 和稳定性，取得了很好的催化效果，还发现全(6-颈 基-6-脱氧)- $\beta$-环糊精覆盖了 Pd 纳米粒子表面的 46\%, 所 以 $\mathrm{Pd}$ 纳米粒子还具有相当的表面积用作催化活性部位. Denicourt-Nowicki 等 ${ }^{[65 ~ 67]}$ 以甲基化 $\beta$-环糊精稳定金属 $\mathrm{Ru}$ 纳米粒子, 催化氢化烯烃, 不仅可以催化氢化还原脂 肪族烯烃, 也可以催化氢化芳环, 并且底物几乎定量转 化. 甲基化 $\beta$-环糊精不仅作为金属 $\mathrm{Ru}$ 纳米粒子的稳定 剂, 也是反应的相转移催化剂, 将底物转移到金属表面, 并控制催化反应的选择性. Hubert 等 ${ }^{[68]}$ 以甲基化 $\beta$-环糊 精和 $N, N$-二甲基- $N$-十六烷基- $N$-(2-羊基乙基)氯化铵共 同作为金属 $\mathrm{Ru}$ 纳米粒子的稳定剂, 催化氢化芳香族烯 烃，二者的协同作用显著提高了 $\mathrm{Ru}$ 纳米粒子的催化活 性，优于其中任何一个单独作用的效果，底物转化率接 近 100\%. Wyrwalski 等 ${ }^{[69]}$ 以甲基化 $\alpha$-环糊精、 $\beta$-环糊精 和 $\gamma$-环糊精稳定零价纳米钉粒子, 然后将其吸附在碳质 载体上，用于催化氢化 $o$-二甲苯、 $m$-二甲苯和 $p$-二甲苯, 其中甲基化 $\beta$-环糊精效果最佳, 具有最好的氢化活性和 立体选择性. 甲基化 $\beta$-环糊精不仅具有分散和稳定零价 纳米钉粒子的作用, 其与氢化底物之间的主客体相互作 用对反应也具有一定的促进作用.
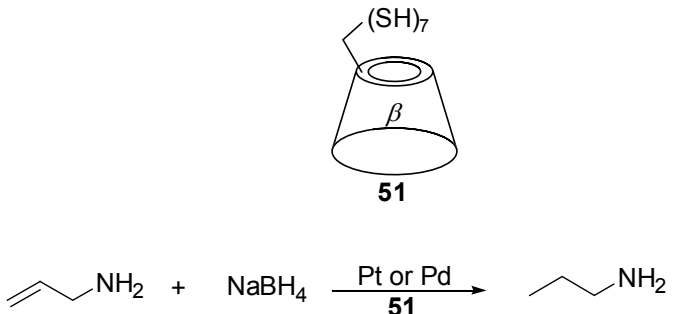

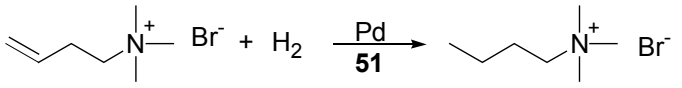

\section{2 偶联反应}

$\mathrm{C}-\mathrm{C}$ 键的形成一直是有机合成方法学中研究的热 点, Suzuki 偶联反应、Heck 偶联反应和 Sonogashira 偶 联反应是形成 $\mathrm{C}-\mathrm{C}$ 键常用的方法. Strimbu 等 ${ }^{[70]}$ 以全(6颈基-6-脱氧)- $\beta$-环糊精(51)修饰贵金属 $\mathrm{Pd}$ 纳米粒子，催 化芳基卤化物和苯基硼酸的 Suzuki 偶联反应(Eq. 9), 取 得了与均相 $\mathrm{Pd}$ 催化剂相同的催化效果. Cassez 等 ${ }^{[71,72]}$ 报道了甲基化 $\beta$-环糊精稳定 $\mathrm{Pd} / \mathrm{C}$ 纳米粒子，催化芳基 碘化物 Suzuki-Miyaura 偶联反应(Eq. 10)和 Heck 偶联反 应(Eq. 11). 甲基化 $\beta$-环糊精提高了 $\mathrm{Pd} / \mathrm{C}$ 和底物的水溶 性，增强了它们在反应体系中的分散，显著提高了反应 速率，并且在 Heck 偶联反应中，由于甲基化 $\beta$-环糊精 空腔的限制, 使产物较多的生成反式异构体. 以甲基化 $\beta$-环糊精稳定水相 $\mathrm{Pd} / \mathrm{C}$, 避免了有机膦配体的使用，价 廉环保. 另外, Senra 等 ${ }^{[73 \sim 75]}$ 也报道了羟丙基 $\alpha$-环糊精 和羟丙基 $\beta$-环糊精作为金属 $\mathrm{Pd}$ 纳米粒子的稳定剂, 催 化 Suzuki 偶联反应、Heck 偶联反应和 Sonogashira 偶联 反应，将底物包结作用和催化活性中心结合起来，不仅 提高了 $\mathrm{Pd}$ 粒子的稳定性，也提高了反应速率.

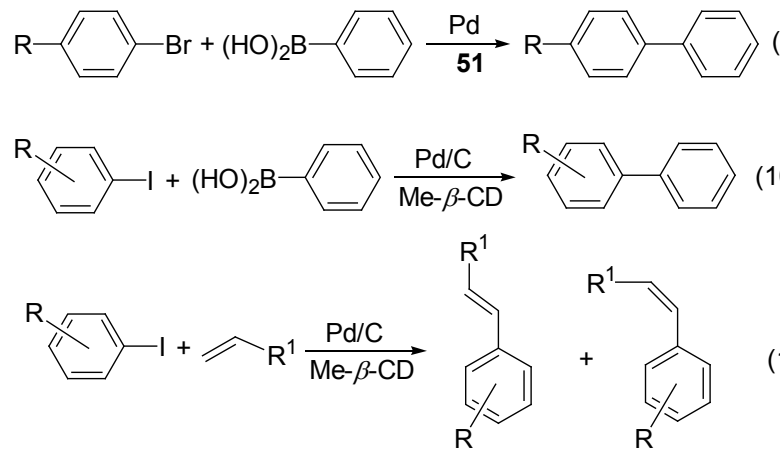

\section{3 氧化反应}

$\beta$-环糊精衍生物修饰贵金属及其氧化物纳米粒子, 催化氧化反应的报道较少. Tachikawa 等 ${ }^{[76]}$ 以羧甲基 $\beta$ 环糊精螯合到 $\mathrm{TiO}_{2}$ 纳米粒子表面，催化芳香族硫化物 单电子光氧化反应，与单独使用 $\mathrm{TiO}_{2}$ 纳米粒子相比, 羧 甲基 $\beta$-环糊精螯合到 $\mathrm{TiO}_{2}$ 纳米粒子表面上，显著促进 了反应的进行. Matta 等 ${ }^{[77]}$ 以羧甲基 $\beta$-环糊精螯合到磁 铁石纳米粒子上，增加了磁铁石纳米粒子在水溶液中的 分散，以此催化氧化 2,4,6-三硝基甲苯，与单独使用磁 铁石相比，将反应速率提高了 3 倍，为治理环境污染物 2,4,6-三硝基甲苯提供了一种方便快捷的方法.

另外, $\mathrm{Li}$ 等 ${ }^{[78]}$ 以全(6-颈基-6-脱氧)- $\beta$-环糊精(51)修 饰 $\mathrm{Au}$ 纳米粒子, 然后与三亚乙基四氨基金刚烷的 $\mathrm{Cu}^{2+}$ 
络合物形成超分子仿生催化剂, 催化水解 4,4'-二硝基苯 基碳酸酯, 将水解速率提高了 2654 倍. $\mathrm{Li}$ 等认为该超分 子催化剂的高催化活性, 可能是多金属催化中心和 $\mathrm{Au}$ 纳米粒子三维结构共同作用的结果.

\section{3 反相相转移催化剂}

环糊精衍生物还可以作为反相相转移催化剂, 用于 水相-有机相两相反应, 通过与底物形成包结络合物, 将底物从有机相转移到两相界面, 与水相中的金属催化 剂接触发生反应. 与常用的季铵盐表面活性剂相比, 环 糊精衍生物作为相转移催化剂反应体系不易形成乳状 液, 含有产物的有机相与含有催化剂的水相很容易得到 分离, 并且水相中的催化剂可以循环使用. 目前文献报 道的环糊精衍生物作为反相相转移催化剂, 主要应用于

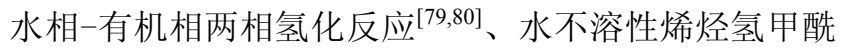
化反应 ${ }^{[81 ~ 84]}$ 、水不溶性烯烃 Wacker 氧化反应 ${ }^{[85,86]}$ 、碳 酸烯丙基酯 Tsuji-Trost 反应 ${ }^{[87,88]}$ 和 Suzuki 偶联反应 ${ }^{[89]}$ 等.

如 Leclercq 等 ${ }^{[00]}$ 报道了甲基化 $\alpha$-环糊精作为反相 相转移催化剂同 $\mathrm{Rh} / \mathrm{P}\left(\mathrm{C}_{6} \mathrm{H}_{4} \mathrm{SO}_{3} \mathrm{Na}\right)_{3}$ 协同催化高级烯烃 氢甲酰化反应(Eq. 12). 由于甲基化增加了 $\alpha$-环糊精的 空腔深度, 有利于其与烯烃的包结, 使水不溶性烯烃进 入水相同催化剂接触反应. 同时, 由于包结作用, 不仅 加速了反应, 而且提高了产物中直链醛的比例, 直链醛 同支链醛的比例均高于不使用相转移催化剂和甲基化 $\beta$-环糊精作为反相相转移催化剂的比例. Leclercq 等 ${ }^{[91]}$ 还研究了 $\alpha$-环糊精、 $\beta$-环糊精、甲基化和羟丙基化的 $\alpha$ 环糊精和 $\beta$-环糊精在有机金属催化烯烃两相氢甲酰化 反应和烷基烯丙基碳酸酯 Tsuji-Trost 反应(Eq. 13)中, 环 糊精及其衍生物在两相界面的吸附与催化活性的关系. 研究发现, 环糊精及其衍生物在两相界面的吸附是水 相-有机相两相金属催化反应的关键因素, 其在两相界 面的吸附量越高, 催化活性越高. 进而提出在环糊精及 其衍生物存在下, 有机金属催化的两相反应反应机理 为: 当底物是水溶性烯烃或碳酸酯时, 其与环糊精及其 衍生物的包结物为水溶性, 有机金属催化反应主要发生 在水相中; 当底物是水不溶性烯烃或碳酸酯时, 其与环 糊精及其衍生物的包结物为水不溶性, 有机金属催化反 应主要发生在水相和有机相的两相界面处.

Tilloy 等 ${ }^{[86]}$ 以 $\beta$-环糊精及其衍生物甲基化 $\beta$-环糊 精、羟乙基 $\beta$-环糊精、羟丙基 $\beta$-环糊精、乙酰基 $\beta$-环糊 精和 $\beta$-环糊精硫酸酯作为反相相转移催化剂, 考察了其 在过渡金属催化十碳-1-烯水相-有机相两相氢甲酰化反 应、氢着基化反应和 Wacker 氧化反应中的相转移性能. 研究发现, 反应收率在很大程度上取决于环糊精取代基

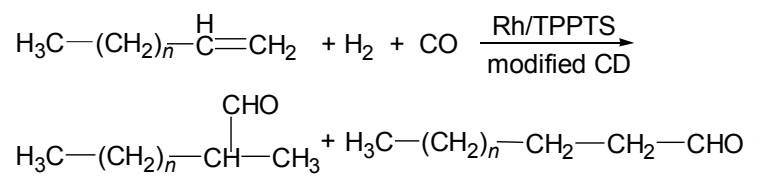

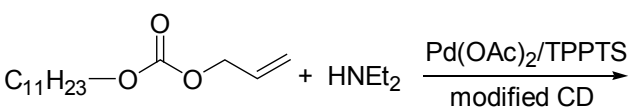

$$
\begin{aligned}
& \mathrm{C}_{11} \mathrm{H}_{23} \mathrm{OH}+\mathrm{CO}_{2}+\mathrm{Et}_{2} \mathrm{~N}
\end{aligned}
$$

的性质和取代度. 全(2,6-二- $O$-甲基)- $\beta$-环糊精在三类反 应中均具有最好的催化效果, 主要是由于全 $(2,6-$ 二- $-O$ 甲基) $-\beta$-环糊精在水相和有机相均具有一定的溶解度, 有利于传质; 羟乙基 $\beta$-环糊精、羟丙基 $\beta$-环糊精在有机 相中溶解性不好, 全甲基化和全乙酰化 $\beta$-环糊精在水相 中溶解性不好, 均具有较差的反应效果. 另外, 环糊精 空腔对底物的识别作用，使该反应体系具有一定的择形 性. 另外, 含有催化剂的水相经简单分离后, 循环利用 5 次而未见反应活性下降，拓展了过渡金属在水相一有 机相两相反应中的应用.

总之, 环糊精衍生物作为反相相转移催化剂主要是 通过与底物形成包结络合物, 将底物由有机相转移到金 属催化剂所在的水相或两相界面, 有利于底物同金属催 化剂的接触, 促进反应进行. 同时, 由于底物与环糊精 衍生物包结作用的存在，也会产生一定的底物选择性或 反应的区域选择性. 另外, 环糊精及其衍生物与底物形 成包结络合物的同时，也可以同金属催化剂的配体形成 包结络合物，造成金属催化剂配位数的减少，有时甚至 造成一定程度的催化剂中毒, 所以, 设计合成结构匹配 的环糊精衍生物及金属催化剂是环糊精衍生物作为反 相相转移催化剂在金属催化水相-有机相两相反应中应 用的关键 ${ }^{[92,93]}$.

\section{4 结论与展望}

通过回顾和总结环糊精衍生物在金属催化有机合 成反应中的应用，不难看出环糊精衍生物在金属催化有 机合成反应中，作为金属离子配体应用最为广泛深入， 其他两方面的应用研究也具有较大潜力, 通过环糊精修 饰基团与金属离子的配位作用形成金属仿酶，模拟生物 金属酶催化氧化和水解反应，还原反应报道还相对较 少. 其中基于环糊精衍生物的金属仿酶中，目前报道的 比较成功的例子为细胞色素 P-450 酶模型和 $\beta, \beta$-胡萝卜 素氧化酶模型. 环糊精衍生物与金属离子形成的金属仿 酶中，由于环糊精部分与底物的包结络合作用，拉近了 底物同催化活性中心金属离子的距离, 并相对固定了底 物与催化活性中心的空间几何位置，可显著提高反应的 反应速率和区域选择性，甚至反应的对映选择性. 而环 
糊精衍生物作为金属纳米粒子稳定剂和反相相转移催 化剂, 主要是作为一种反应助剂, 辅助主催化剂催化有 机合成反应，在这里环糊精衍生物主要是作为催化中心 的稳定剂或反应的传质促进剂. 但无论环糊精衍生物在 金属催化有机合成反应中扮演何种角色，其很重要的原 因是因为环糊精空腔部分可以对底物进行包结, 并且其 本身溶于水，能够像酶一样为底物提供疏水环境，同时 该包结络合物溶于水，在水相中顺利实现有机合成转 化.

环糊精具有疏水空腔的结构, 使其天生成为构筑像 酶一样具有疏水结构的超分子仿生催化剂的结构单元, 尤其是价廉易得的 $\beta$-环糊精，应用最广，除特殊例子外， 环糊精衍生物基本是指 $\beta$-环糊精衍生物. 并且环糊精衍 生物或其金属离子络合物催化有机合成反应，基本在水 相中进行, 避免了有机溶剂的使用, 并且环糊精本身无 毒可再生, 环保绿色, 符合绿色化学的理念. 同时, 氧 化反应与水解反应是生物体内普遍存在的生物转化过 程, 通过深入研究环糊精衍生物与金属离子形成金属仿 酶催化氧化反应和水解反应的反应机理, 有利于我们更 加深入的了解生物体内物质的转化过程, 为探明生命科 学领域中普遍存在的分子识别, 选择性转化及药物代谢 过程提供基础理论参考. 因此, 开发高效、高选择性的 环糊精衍生物及其金属离子络合物，作为超分子仿生催 化剂催化有机合成反应, 将继续是人们研究的热点. 对 于环糊精衍生物作为反相相转移催化剂，同传统方法使 用表面活性剂作为相转移催化剂相比，反应体系不易形 成乳状液, 体系各组分分离容易. 因此, 环糊精衍生物 作为反相相转移催化剂将可能会逐步取代传统方法中 使用的表面活性剂, 有利于两相反应的操作与分离纯 化, 为开发合成新型表面活性剂作为相转移催化剂应用 于有机合成反应提供了一个新的方向.

\section{References}

[1] Sallas, F.; Darcy, R. Eur. J. Org. Chem. 2008, 957.

[2] Ji, H. B.; Huang, L. Q.; Shi, D. P.; Zhou, X. T. Chin. J. Org. Chem. 2008, 28, 2072 (in Chinese). (纪红兵, 黄丽泉, 石东坡, 周贤太, 有机化学, 2008, 28, 2072.)

[3] Engeldinger, E.; Armspach, D.; Matt, D. Chem. Rev. 2003, 103, 4147.

[4] Khan, A. R.; Forgo, P.; Stine, K. J.; D'Souza, V. T. Chem. Rev. 1998, 98,1977

[5] An, W.; Zhang, H. C.; Sun, T.; Li, X. J.; Hao, A. Y. Chin. J. Org Chem. 2011, 31, 275 (in Chinese)

(安伟, 张华承, 孙涛, 李祥军, 郝爱友, 有机化学, 2011, 31, 275.)

[6] Breslow, R. Acc. Chem. Res. 1995, 28, 146.

[7] Bjerre, J.; Rousseau, C.; Marinescu, L.; Bols, M. Appl. Microbiol. Biotechnol. 2008, 81, 1.

[8] Hu, S. S.; Li, J. Y.; Xiang, J. F.; Pan, J.; Luo, S. Z.; Cheng, J. P. J. Am. Chem. Soc. 2010, 132, 7216.
[9] Shen, H. M.; Ji, H. B. Chin. J. Org. Chem. 2011, 31, 791 (in Chinese).

(沈海民, 纪红兵, 有机化学, 2011, 31, 791.)

[10] Yang, C.; Mori, T.; Wada, T.; Inoue, Y. New J. Chem. 2007, 31, 697.

[11] Ikeda, H.; Nihei, T.; Ueno, A. J. Inclusion Phenom. Macrocylic Chem. 2004, 50, 63 .

[12] Breslow, R.; Steven, D. D. Chem. Rev. 1998, 98, 1997.

[13] Bellia, F.; La Mendola, D.; Pedone, C.; Rizzarelli, E.; Saviano, M.; Vecchio, G. Chem. Soc. Rev. 2009, 38, 2756

[14] Woggon, W. D. Curr. Org. Chem. 2010, 14, 1362.

[15] Bricout, H.; Hapiot, F.; Ponchel, A.; Tilloy, S.; Monflier, E. Sustainability 2009, 1, 924 .

[16] Denicourt-Nowicki, A.; Roucoux, A. Curr. Org. Chem. 2010, 14, 1266.

[17] Hapiot, F.; Ponchel, A.; Tilloy, S.; Monflier, E. C. R. Chim. 2011, 14,135

[18] Hapiot, F.; Leclercq, L.; Azaroual, N.; Fourmentin, S.; Tilloy, S.; Monflier, E. Curr. Org. Synth. 2008, 5, 162.

[19] Bricout, H.; Hapiot, F.; Ponchel, A.; Tilloy, S.; Monflier, E. Curr. Org. Chem. 2010, 14, 1296.

[20] Ji, H. B. Eur. J. Org. Chem. 2003, 3659.

[21] Ji, H. B.; Shi, D. P.; Shao, M.; Li, Z.; Wang, L. F. Tetrahedron Lett. 2005, 46, 2517.

[22] Chen, H. Y.; Ji, H. B. AIChE J. 2010, 56, 466.

[23] Ji, H. B.; Chen, H. Y.; Zhou, X. T.; Wang, L. F. Tetrahedron 2010, $66,9888$.

[24] Ji, H. B.; Huang, L. Q.; Shen, H. M.; Zhou, X. T. Chem. Eng. J. 2011, 167, 349.

[25] Breslow, R.; Zhang, X.; Xu, R.; Maletic, M.; Merger, R. J. Am. Chem. Soc. 1996, 118, 11678.

[26] Karakhanov, E.; Maximov, A.; Kirillov, A. J. Mol. Catal. A: Chem. 2000, 157, 25.

[27] French, R. R.; Holzer, P.; Leuenberger, M. G.; Woggon, W. D. Angew. Chem., Int. Ed. 2000, 39, 1267.

[28] French, R. R.; Holzer, P.; Leuenberger, M.; Nold, M. C.; Woggon, W. D. J. Inorg. Biochem. 2002, 88, 295.

[29] Breslow, R.; Zhang, X.; Huang, Y. J. Am. Chem. Soc. 1997, 119, 4535.

[30] Yang, J.; Breslow, R. Angew. Chem., Int. Ed. 2000, 39, 2692.

[31] Yang, J.; Gabriele, B.; Belvedere, S.; Huang, Y.; Breslow, R. J. Org. Chem. 2002, 67, 5057.

[32] Breslow, R.; Yan, J. M.; Belvedere, S. Tetrahedron Lett. 2002, 43, 363.

[33] Breslow, R.; Yang, J.; Yan, J. M. Tetrahedron 2002, 58, 653.

[34] Bonchio, M.; Carofiglio, T.; Di Furia, F.; Fornasier, R. J. Org. Chem. 1995, 60, 5986.

[35] Sakuraba, H.; Maekawa, H. J. Inclusion Phenom. Macrocyclic Chem. 2006, 54, 41 .

[36] Bonchio, M.; Carofiglio, T.; Carraro, M.; Fornasier, R.; Tonellato, U. Org. Lett. 2002, 4, 4635.

[37] Kano, K.; Kitagishi, H.; Dagallier, C.; Kodera, M.; Matsuo, T.; Hayashi, T.; Hisaeda, Y.; Hirota, S. Inorg. Chem. 2006, 45, 4448.

[38] Dong, S. D.; Breslow, R. Tetrahedron Lett. 1998, 39, 9343.

[39] Kim, D. H.; Lee, S. S. Bioorg. Med. Chem. 2000, 8, 647.

[40] Barr, L.; Easton, C. J.; Lee, K.; Lincoln, S. F.; Simpson, J. S. Tetrahedron Lett. 2002, 43, 7797.

[41] Li, X. Q.; Liang, K.; Wang, C. Y.; Bai, X. L.; Xu, J. Y.; Shen, J. C.; Liu, J. Q. J. Mol. Catal. A: Chem. 2008, 295, 47.

[42] Breslow, R.; Zhang, B. J. Am. Chem. Soc. 1992, 114, 5882.

[43] Breslow, R.; Zhang, B. J. Am. Chem. Soc. 1994, 116, 7893.

[44] Zhang, B.; Breslow, R. J. Am. Chem. Soc. 1997, 119, 1676. 
[45] Jeon, W. B.; Bae, K. H.; Byun, S. M. J. Inorg. Biochem. 1998, 71, 163.

[46] Sallas, F.; Marsura, A.; Petot, V.; Pinter, I.; Kovacs, J.; Jicsinszky, L. Helv. Chim. Acta 1998, 81, 632.

[47] Yan, J. M.; Breslow, R. Tetrahedron Lett. 2000, 41, 2059.

[48] Luo, M. M.; Xie, R. G.; Xia, P. F.; Tao, L.; Yuan, D. Q.; Zhao, H. M. J. Phys. Org. Chem. 2001, 14, 515.

[49] Zhou, Y. H.; Zhao, M.; Mao, Z. W.; Ji, L. N. Chem.-Eur. J. 2008, 14, 7193 .

[50] Zhou, Y. H.; Zhao, M.; Li, J. H.; Mao, Z. W.; Ji, L. N. J. Mol. Catal. A: Chem. 2008, 293, 59.

[51] Zhou, Y. H.; Zhao, M.; Sun, H. Z.; Mao, Z. W.; Ji, L. N. J. Mol. Catal. A: Chem. 2009, 308, 61.

[52] Tang, S. P.; Zhou, Y. H.; Chen, H. Y.; Zhao, C. Y.; Mao, Z. W.; Ji, L. N. Chem.-Asian J. 2009, 4, 1354.

[53] Tang, S. P.; Chen, S.; Wu, G. F.; Chen, H. Y.; Mao, Z. W.; Ji, L. N. Inorg. Chem. Commun. 2011, 14, 184.

[54] Zhao, M.; Wang, H. L.; Zhang, L.; Zhao, C. Y.; Ji, L. N.; Mao, Z. W. Chem. Commun. 2011, 47, 7344.

[55] Nakajima, H.; Sakabe, Y.; Ikeda, H.; Ueno, A. Bioorg. Med. Chem. Lett. 2004, 14, 1783.

[56] Reetz, M. T.; Waldvogel, S. R. Angew. Chem., Int. Ed. 1997, 36, 865.

[57] Wong, Y. T.; Yang, C.; Ying, K. C.; Jia, G. C. Organometallics 2002, 21, 1782 .

[58] Schlatter, A.; Kundu, M. K.; Woggon, W. D. Angew. Chem., Int. Ed. 2004, 43, 6731.

[59] Schlatter, A.; Woggon, W. D. Adv. Synth. Catal. 2008, 350, 995.

[60] Yuan, D. Q.; Lu, J. Z.; Atsumi, M.; Izuka, A.; Kai, M.; Fujita, K. Chem. Commun. 2002, 730.

[61] Yuan, D. Q.; Lu, J.; Atsumi, M.; Yan, J. M.; Kai, M.; Fujita, K. Org. Biomol. Chem. 2007, 5, 2932.

[62] Suresh, P.; Pitchumani, K. J. Org. Chem. 2008, 73, 9121.

[63] Alvarez, J.; Liu, J.; Roman, E.; Kaifer, A. E. Chem. Commun. 2000, 1151.

[64] Liu, J.; Alvarez, J.; Ong, W.; Roman, E.; Kaifer, A. E. Langmuir 2001, 17, 6762 .

[65] Denicourt-Nowicki, A.; Zhang, Y.; Leger, B.; Rolland, J. P.; Bricout, H.; Monflier, E.; Roucoux, A. Chem. Commun. 2006, 296.

[66] Denicourt-Nowicki, A.; Ponchel, A.; Monflier, E.; Roucoux, A. Dalton Trans. 2007, 5714.

[67] Denicourt-Nowicki, A.; Roucoux, A.; Wyrwalski, F.; Kania, N.; Monflier, E.; Ponchel, A. Chem.-Eur. J. 2008, 14, 8090.

[68] Hubert, C.; Denicourt-Nowicki, A.; Roucoux, A.; Landy, D.; Leger, B.; Crowyn, G.; Monflier, E. Chem. Commun. 2009, 1228.

[69] Wyrwalski, F.; Leger, B.; Lancelot, C.; Roucoux, A.; Monflier, E.; Ponchel, A. Appl. Catal., A 2011, 391, 334.

[70] Strimbu, L.; Liu, J.; Kaifer, A. E. Langmuir 2003, 19, 483.

[71] Cassez, A.; Ponchel, A.; Hapiot, F.; Monflier, E. Org. Lett. 2006, 8,
4823.

[72] Cassez, A.; Kania, N.; Hapiot, F.; Fourmentin, S.; Monflier, E.; Ponchel, A. Catal. Commun. 2008, 9, 1346.

[73] Senra, J. D.; Malta, L. F. B.; de Souza, A. L. F.; Medeiros, M. E.; Aguiar, L. C. S.; Antunes, O. A. C. Tetrahedron Lett. 2007, 48, 8153.

[74] Senra, J. D.; Malta, L. F. B.; Souza, A. L. F.; Aguiar, L. C. S.; Antunes, O. A. C. Adv. Synth. Catal. 2008, 350, 2551.

[75] Senra, J. D.; Malta, L. F. B.; da Costa, M. E. H. M.; Michel, R. C.; Aguiar, L. C. S.; Simas, A. B. C.; Antunes, O. A. C. Adv. Synth. Catal. 2009, 351, 2411.

[76] Tachikawa, T.; Tojo, S.; Fujitsuka, M.; Majima, T. Chem.-Eur. J. 2006, 12, 7585.

[77] Matta, R.; Hanna, K.; Kone, T.; Chiron, S. Chem. Eng. J. 2008, $144,453$.

[78] Li, X. Q.; Qi, Z. H.; Liang, K.; Bai, X. L.; Xu, J. Y.; Liu, J. Q.; Shen, J. C. Catal. Lett. 2008, 124, 413.

[79] Monflier, E.; Tilloy, S.; Castanet, Y.; Mortreux, A. Tetrahedron Lett. 1998, 39, 2959.

[80] Tilloy, S.; Bricout, H.; Monflier, E. Green Chem. 2002, 4, 188.

[81] Kirschner, D.; Jaramillo, M.; Green, T.; Hapiot, F.; Leclercq, L.; Bricout, H.; Monflier, E. J. Mol. Catal. A: Chem. 2008, 286, 11.

[82] Legrand, F. X.; Sauthier, M.; Flahaut, C.; Hachani, J.; Elfakir, C.; Fourmentin, S.; Tilloy, S.; Monflier, E. J. Mol. Catal. A: Chem. 2009, 303, 72 .

[83] Dabbawala, A. A.; Parmar, J. N.; Jasra, R. V.; Bajaj, H. C.; Monflier, E. Catal. Commun. 2009, 10, 1808.

[84] Badi, N.; Guegan, P.; Legrand, F.-X.; Leclercq, L.; Tilloy, S.; Monflier, E. J. Mol. Catal. A: Chem. 2010, 318, 8.

[85] Monflier, E.; Tilloy, S.; Blouet, E.; Barbaux, Y.; Mortreux, A. J. Mol. Catal. A: Chem. 1996, 109, 27.

[86] Tilloy, S.; Bertoux, F.; Mortreux, A.; Monflier, E. Catal. Today 1999, 48, 245.

[87] Cabou, J.; Bricout, H.; Hapiot, F.; Monflier, E. Catal. Commun. 2004, 5, 265.

[88] Blach, P.; Landy, D.; Fourmentin, S.; Surpateanu, G.; Bricout, H.; Ponchel, A.; Hapiot, F.; Monflier, E. Adv. Synth. Catal. 2005, 347, 1301.

[89] Hapiot, F.; Lyskawa, J.; Bricout, H.; Tilloy, S.; Monflier, E. Adv. Synth. Catal. 2004, 346, 83.

[90] Leclercq, L.; Sauthier, M.; Castanet, Y.; Mortreux, A.; Bricout, H.; Monflier, E. Adv. Synth. Catal. 2005, 347, 55.

[91] Leclercq, L.; Bricout, H.; Tilloy, S.; Monflier, E. J. Colloid Interface Sci. 2007, 307, 481.

[92] Monflier, E.; Bricout, H.; Hapiot, F.; Tilloy, S.; Aghmiz, A.; Masdeu-Bulto, A. M. Adv. Synth. Catal. 2004, 346, 425.

[93] Canipelle, M.; Tilloy, S.; Ponchel, A.; Bricout, H.; Monflier, E. J. Inclusion Phenom. Macrocyclic Chem. 2005, 51, 79. 